\title{
Effect of Opening on Behavior of Raft Foundations Resting on Different Types of Sand Soil
}

\author{
Mohamed Saad Eldin \\ Assistant Professor of soil \\ mechanics and foundations, \\ Department of Civil Engineering, \\ Al-Azhar University.
}

\author{
Arafa El-Helloty \\ Associated Professor of structures, \\ Department of Civil Engineering, \\ Al-Azhar University.
}

\begin{abstract}
In this paper, the elasto - plastic finite element analysis is carried out using the three-dimensional PLAXIS program to study the effect of opening position and type of soil on behavior ofraft foundations under columns loads. The analysis has been done for raft foundations with middle, edge, and corner opening positions and the results are obtained for three different types of soil which are loose sand, medium dense sand and dense sand soil. The effect of opening positions and type of soilon behavior of raft foundations is presented in graphical form and it is discussed.
\end{abstract}

\section{Keywords}

Raft foundation, mat foundation, soil, opening, loose sand, medium dense sand, dense sand, settlement, moment.

\section{INTRODUCTION}

Raft or mat foundation is one of the effective types of shallow foundations which it carries the load to the soil without any differential settlement in the soil. A raft foundation may be used when the base soil has a low bearing capacityand it may be used when the foundation settlement is bigger than the allowable settlement. Also, a raft foundation is used when the columns loads are so large that more than 50 percent of the area is covered by conventional spread footings. Extensive research work has been carried out and published in the past decades and different analysis methods have been developed to design the raft foundations which are varying from conventional manual calculation methods to most modern computer based methods.[1-7,9,10]

In the design of raft foundations, the soil can be treated as a series of individual springs which known as a Winkler model or as a continuum. The Winkler model treats the soil as a series of springs and it assumes that the pressure at any point on the surface of the soil is related to the modulus of subgrade reaction which is known as the Winkler spring stiffness and the deflection of the soil.The spring stiffness depends on the settlement characteristic of the soil and the geometry of the foundation. This model can be easily handled by mathematical equations and it can produce reasonably accurate results. However, it neglects the interaction between each individual spring and the supporting soil that it is not modeled as a continuum. An alternative approach that treats the supporting soil as an elastic continuum can better represent the physical behavior of the supported soil. The soil parameters used in this approach depend on the field stress state. $[1-7,9,10]$
Openings may be found in raft foundations to access ports for mechanical, electrical systems and hydraulic lines. These openings will result in high stress concentrations at the vicinity of the opening, change the mechanical behavior of raft and complicate the stress distribution in the raft. Hence, the analysis of such raft structures is essential for understanding the behavior of complex structures with openings. In the literature, most studies in the analysis of raft foundations have been focused on rafts which are continuous and resting on elastic springs which are Winkler model.[1-10]

Therefore, the aim of this study is to demonstrate the effect of opening position and type of soil on the behavior of raft foundations using the finite element programPLAXIS 3D. Square raft foundations loaded with columns loads are considered resting onthree different types ofsoil which are loose sand, medium dense sand and dense sand. Three opening positions are considered in the raft and the analysis for settlementsof soil and moments in raft are carried out.

\section{NUMERICAL EXAMPLE}

To study the effect of opening position and type of soil on the behavior of raft foundations, the analysis of a square raft resting on soil with thickness $0.8 \mathrm{~m}$ is considered under six columns loads as shown in Fig. 1. The dimensions of the reference raft which is a raft without an opening are $10.0 \mathrm{~m} \mathrm{x}$ $10.0 \mathrm{~m}$ as shown in Fig.1-a.

Square opening is made in the raft with dimensions $2.0 \mathrm{~m} \mathrm{x}$ $2.0 \mathrm{~m}$ and three opening positions are considered which are at the middle, at the edge and at the corner of the raft as shown in Fig. 1 (b, c and d) to show the effect of variation of the opening position on the behavior of raft foundations. To study the effect of soil type on the behavior of raft foundations, three different types of soil are considered which are loose sand, medium dense sand and dense sand.To avoid boundary effects, the finite element model of soil is represented by area $50.0 \mathrm{~m} \times 50.0 \mathrm{~m}$ with depth $40.0 \mathrm{~m}$.

The materials properties for raft and soil are given as following:

For raft foundation, $\mathrm{E}=30 \times 10^{6} \mathrm{KN} / \mathrm{m}^{2}$ and $v=0.2$ for elastic modulus of elasticity and Poisson's ratio respectively. For loose sand, $\gamma_{\mathrm{d}}=16 \mathrm{KN} / \mathrm{m}^{3}, \mathrm{E}=10000 \mathrm{KN} / \mathrm{m}^{2}, \Phi=30$ and $v=0.30$ for unit weight, elastic modulus of elasticity, angle of internal friction and Poisson's ratio respectively. For medium dense sand, $\gamma_{\mathrm{d}}=17 \mathrm{KN} / \mathrm{m}^{3}, \mathrm{E}=30000 \mathrm{KN} / \mathrm{m}^{2}, \Phi=35$ and $v=$ 0.35 for unit weight, elastic modulus of elasticity, angle of internal friction and Poisson's ratio respectively. 
For dense sand, $\gamma_{\mathrm{d}}=18 \mathrm{KN} / \mathrm{m}^{3}, \mathrm{E}=50000 \mathrm{KN} / \mathrm{m}^{2}, \Phi=40$, and $v=0.40$ for unit weight, elastic modulus of elasticity, angle of internal friction and Poisson's ratio respectively.

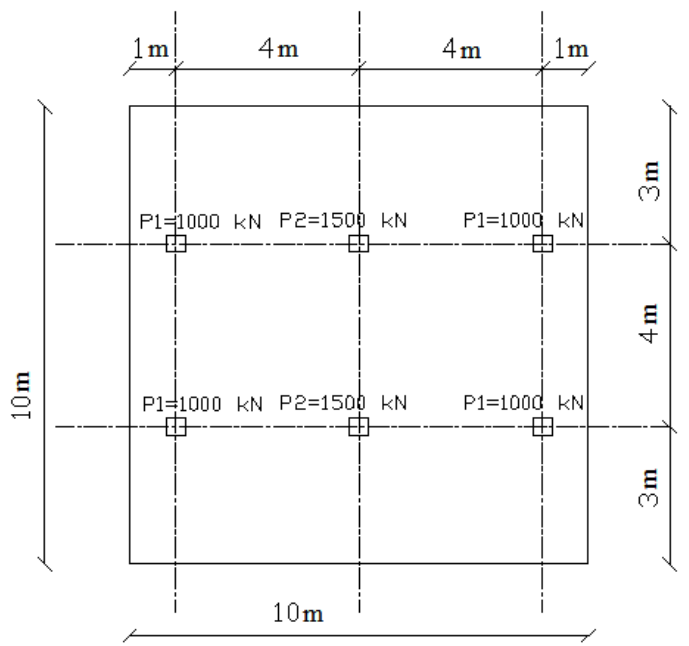

Fig 1-a: Raft without opening (Reference raft)

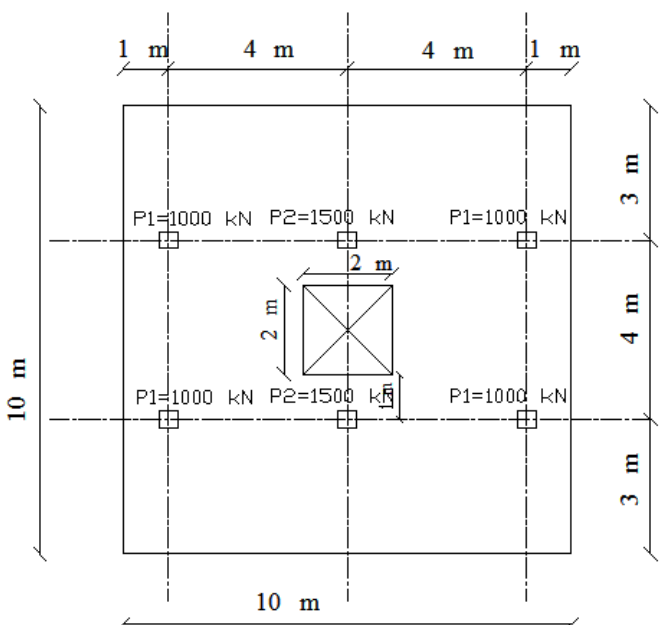

Fig 1-b: Raft with mid opening

Fig 1-c: Raft with edge opening

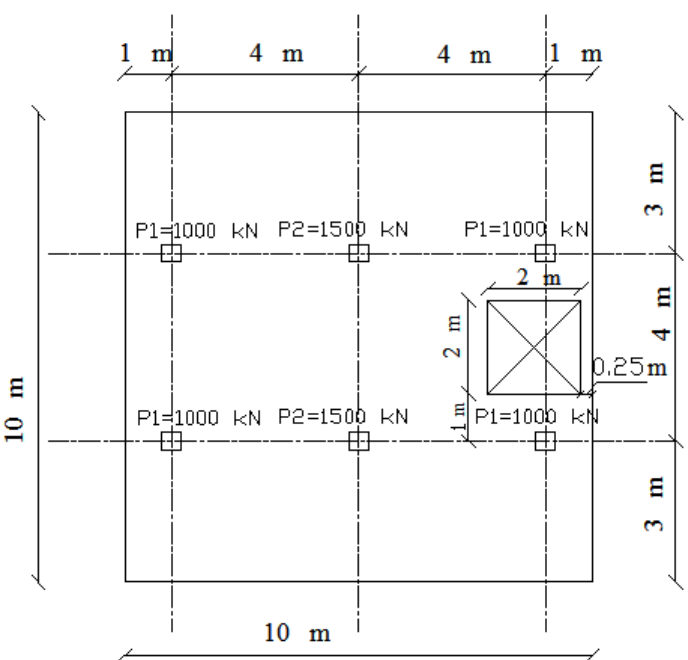

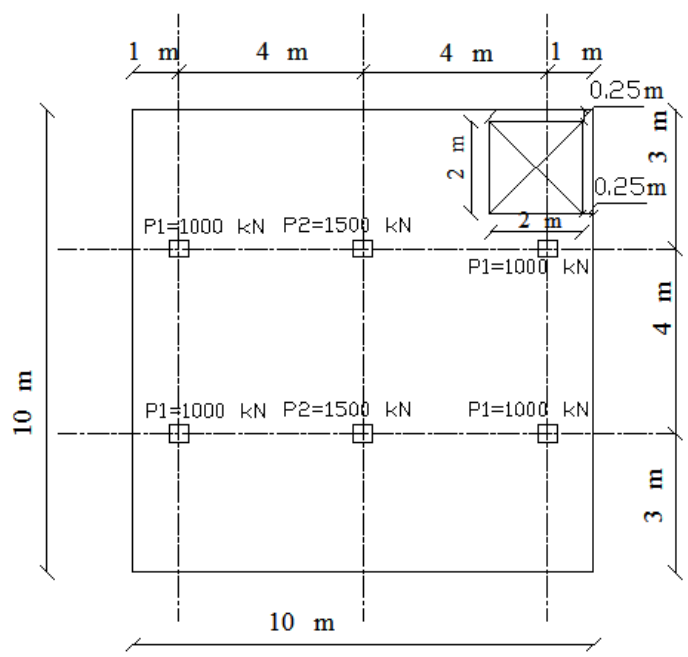

Fig 1-d: Raft with corner opening

\section{METHOD OF ANALYSIS}

The elasto-plastic finite element analysis has been done by the 15-node wedge element in three-dimensional PLAXIS program as shown in Fig. 2. The 15-node wedge element is composed of 6-node triangles in horizontal direction and 8node quadrilaterals in vertical direction. The accuracy of the 15-node wedge element and the compatible structural elements are comparable with the 6-node triangular element and compatibles in a 2D PLAXIS analysis. Due to the presence of non-horizontal soil layers, some 15-node wedge elements may degenerate to 13-node pyramid elements or even to 10-node tetrahedral elements.[8]

The discreation of both soil and raft has been done using the automatically mesh generation method in PLAXIS program with local refinement. The local refinement is used in areas where large stress concentrations or large deformation gradients are expected and it is desirable to have a more accurate finite element mesh whereas other parts of the geometry may not require a fine mesh in order to reduce the computational efforts.[8]

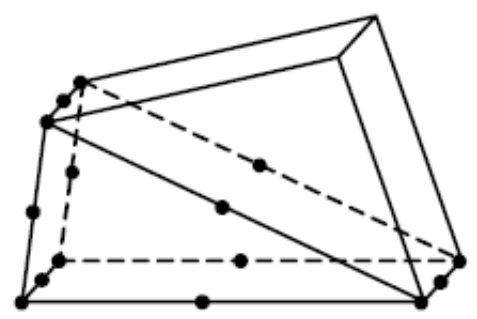

Fig 2: 15-node wedge element in 3D PLAXIS program

\section{RESULTS AND DISCUSSION}

The 3D finite element meshes for soil and raft without and with openings are shown in Fig 3. The analysis has been carried out and the settlement of soil and moment in raft for the reference raft and the rafts with opening are obtained. For example, Fig. 4 presents contours of settlement and values of settlement in different types of soil due to Reference raft and Fig. 5 presents contours of moment in raft foundation resting on loose sand soil without and with opening. 


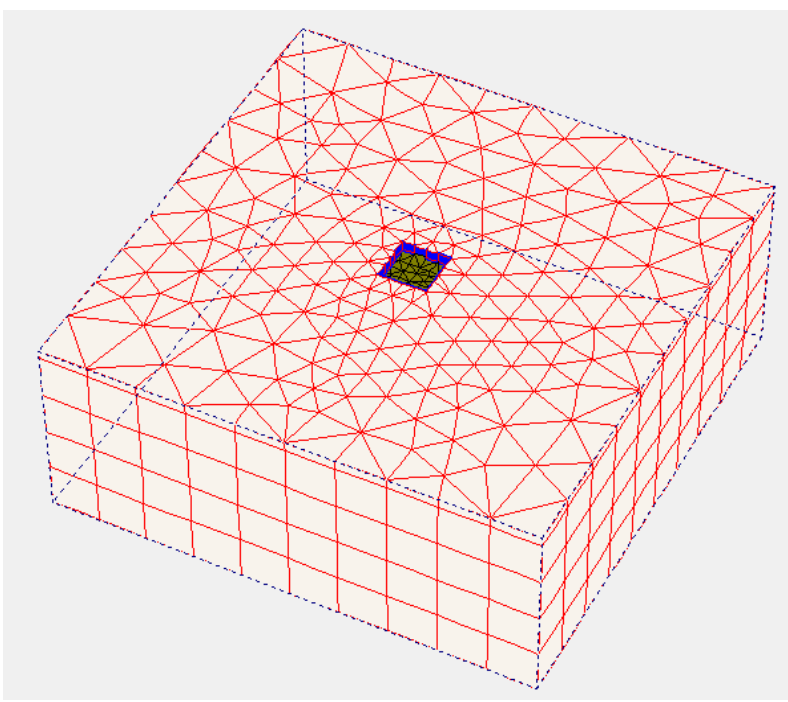

a-Reference raft

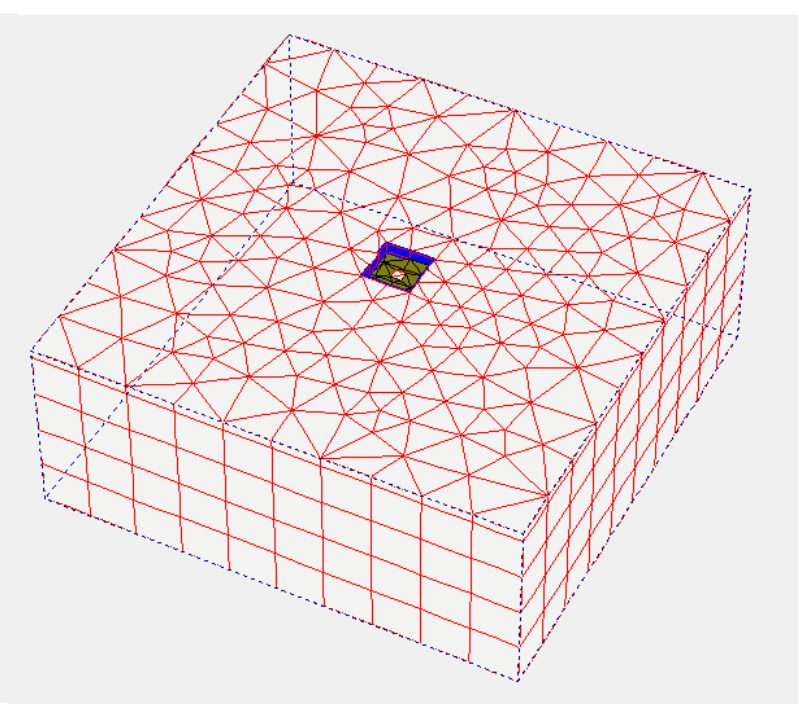

b-Raft with mid opening

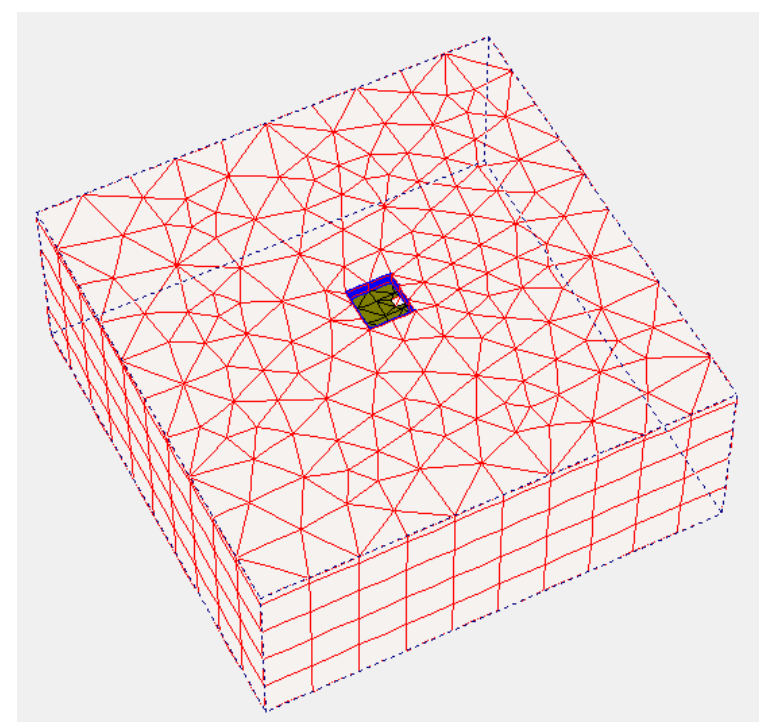

c- Raft with edge opening

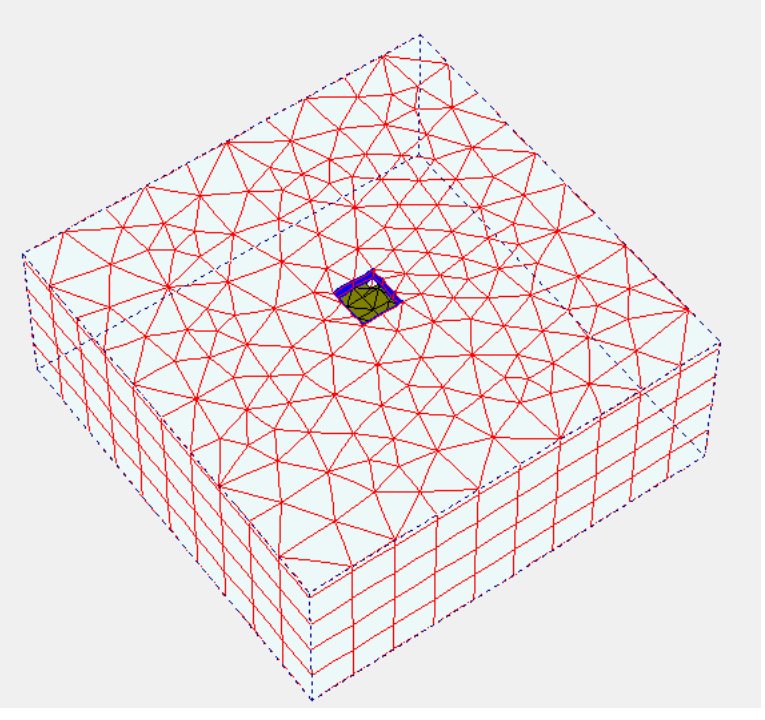

d- Raft with corner opening

Fig 3: 3D Finite element meshes for soil and raft foundations with and without openings 


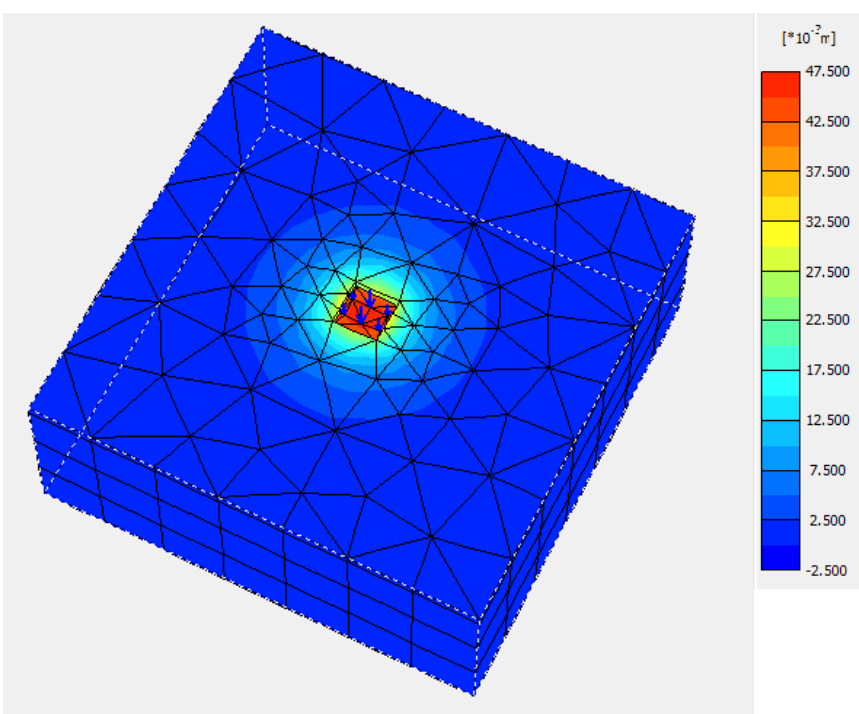

a-Settlement of loose sand soil.

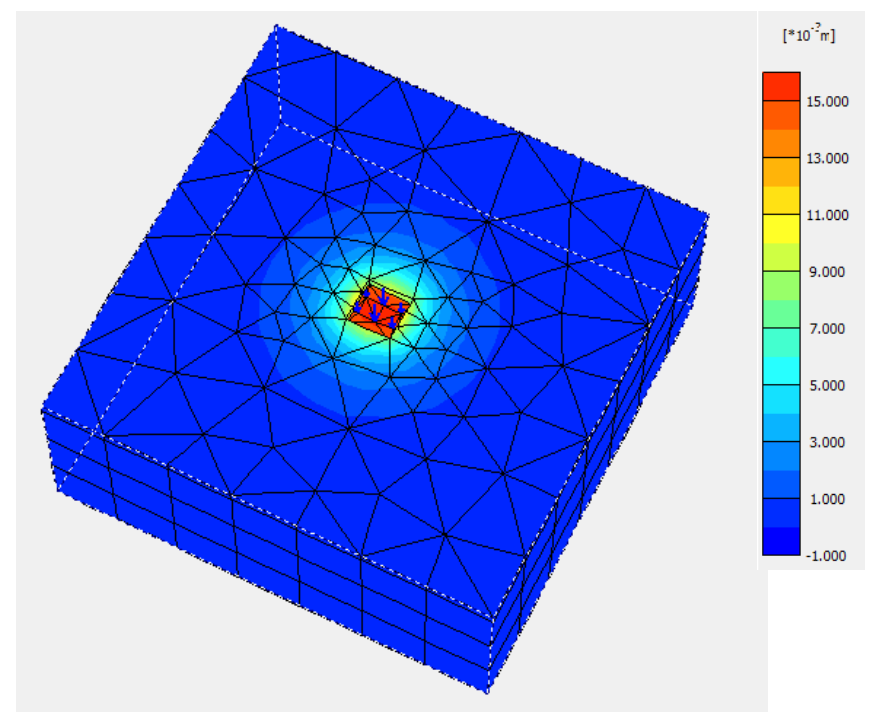

b- Settlement of medium dense sand soil

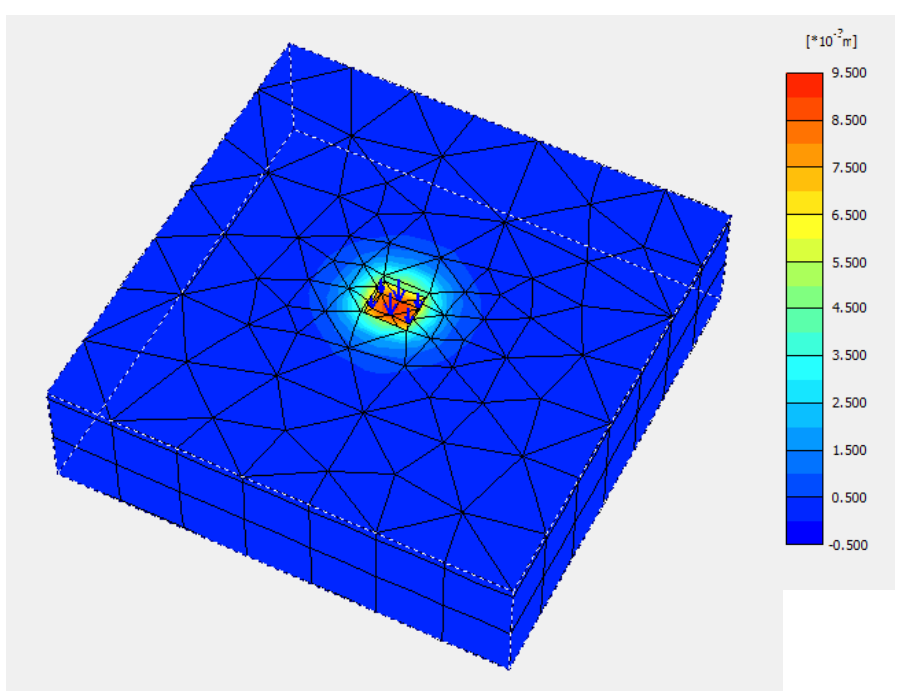

c- Settlement of dense sand soil

Fig 4: Contours of settlement for different types of sand soil due to Reference raft 


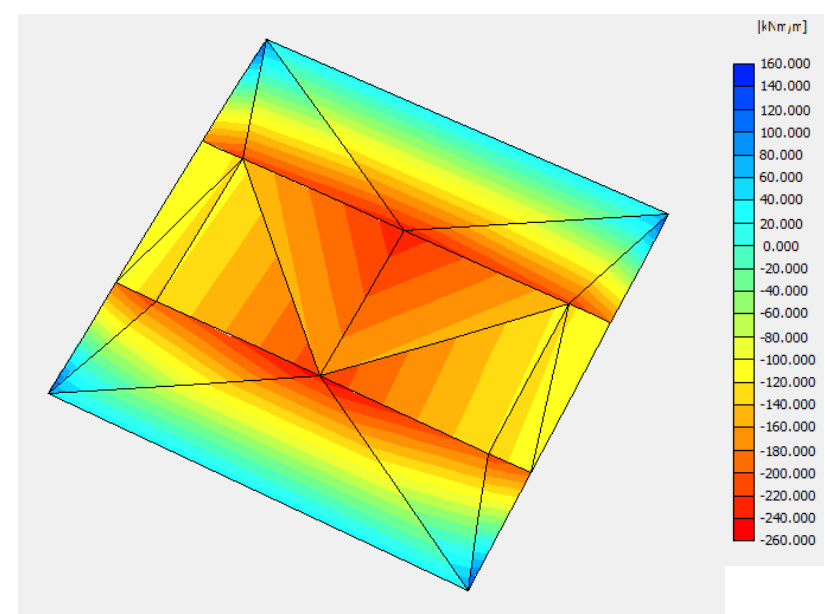

a-Reference raft

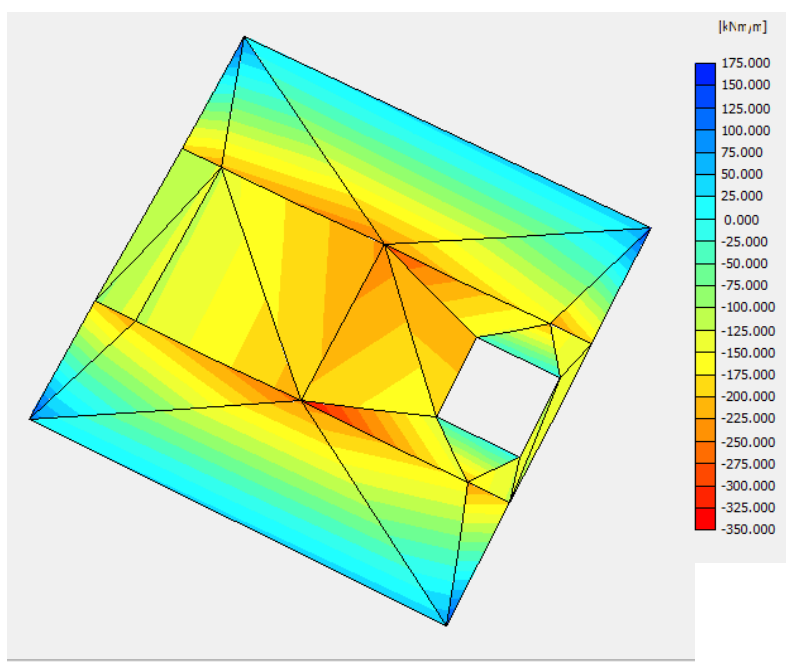

c- Raft with edge opening

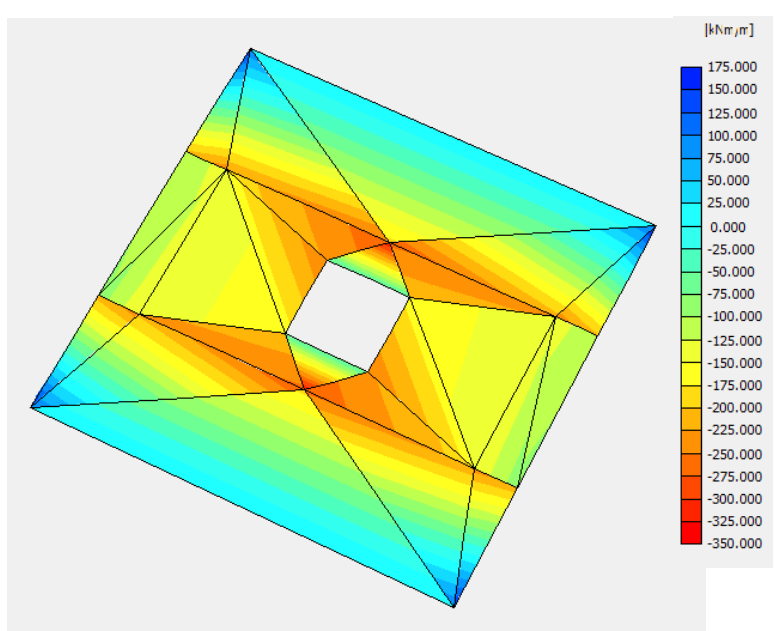

b- Raft with mid opening

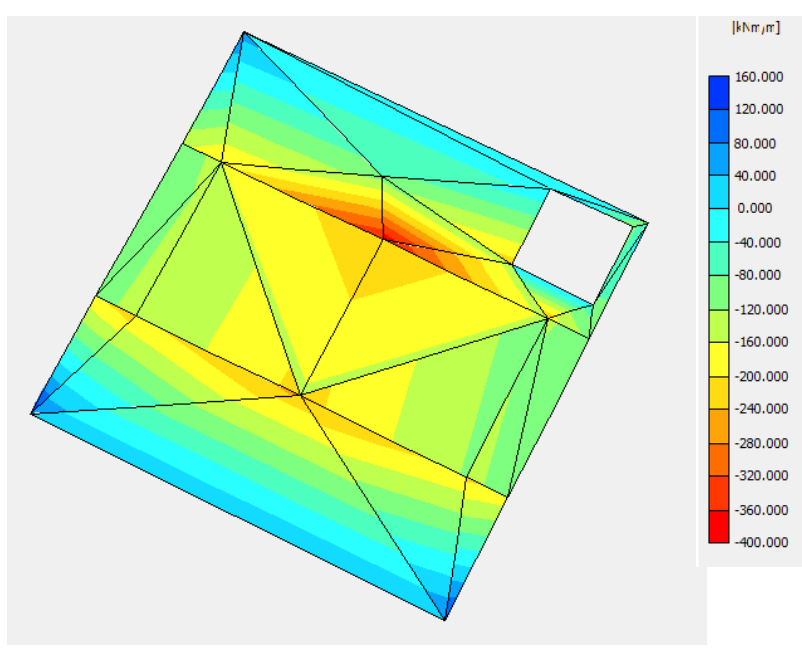

d- Raft with corner opening

Fig 5: Distribution of moments in raft foundation resting on loose sand soil without and with opening 
To study the effect of opening position and type of soil on the behavior of raft foundations, the results obtained by the nonlinear analysis are analyzed. For simplicity, the results are presented by charts as follows:

Fig. 6 presents the effect of opening positions on the performance of the settlement of soilfor different types of soil.Fig. 7 present the comparison of opening positions on the settlement of soil for different types of soil. Fig. 8 presents the effect of opening positions on the performance of the moment in direction $\mathrm{X}$ in raft foundation for different types of soil.Fig.9 presents the comparison of opening positions on the moment in direction $\mathrm{X}$ in raft foundation for different types of soil. Fig. 10 presents the effect of type of soil on the performance of the settlement of soil for different opening positions. Fig.11 presents thecomparison of type of soil on the settlement of soil for different opening positions.Fig.12 presents the effect of type of soil on the performance of the moment in direction $\mathrm{X}$ in raft foundation for different opening positions. Fig. 13 presents the comparison of type of soil on the moment in direction $\mathrm{X}$ in raft foundationfor different opening positions.

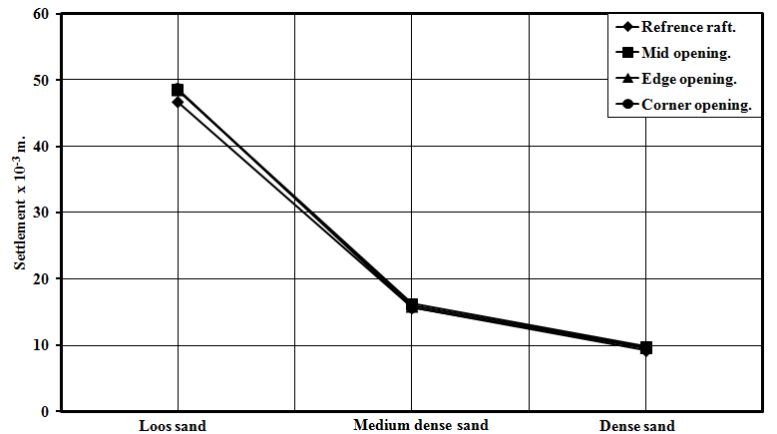

Fig 6: Effect of opening positions on the performance of the settlement of soilfor different types of soil

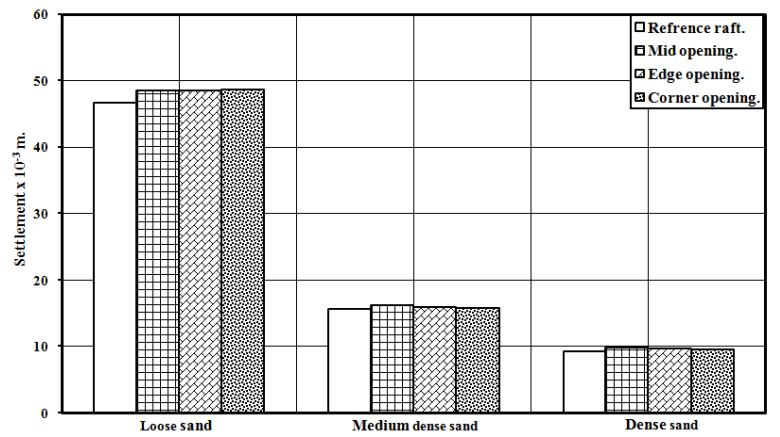

Fig 7: Comparison of opening positions on the settlement of soil for different types of soil

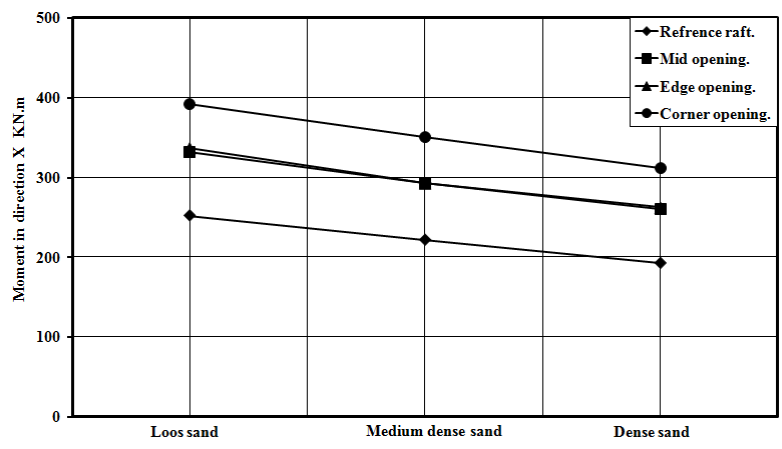

Fig 8: Effect of opening positions on the performance of the moment in direction $\mathrm{X}$ in raft foundation for different types of soil

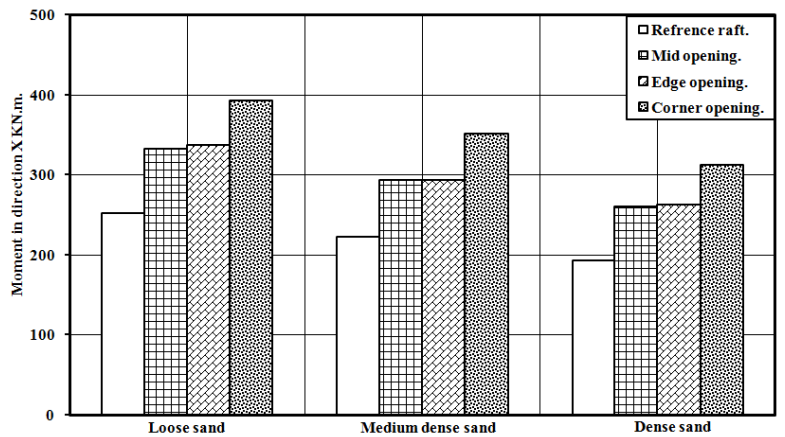

Fig 9: Comparison of opening positions on the moment in direction $\mathrm{X}$ in raftfoundation for different types of soil

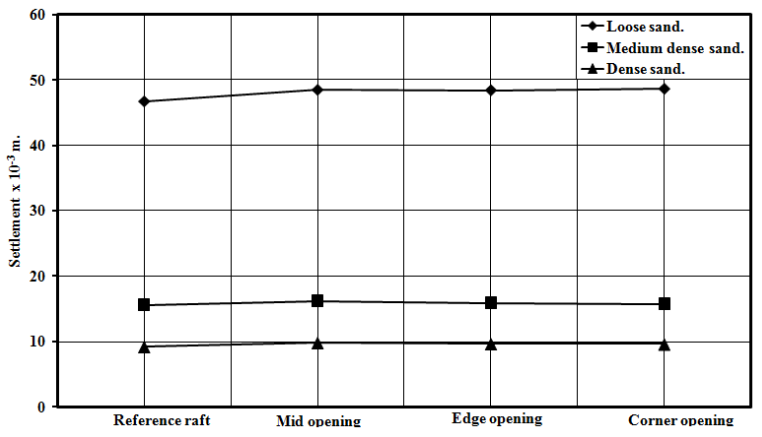

Fig 10: Effect of type of soil on the performance of the settlement of soil for different opening positions

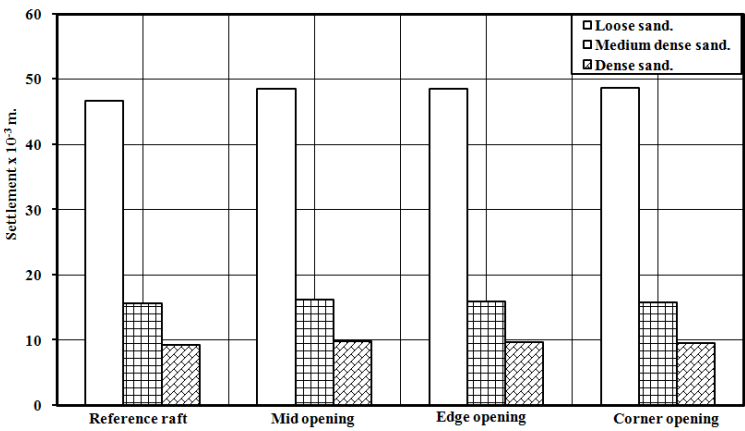

Fig 11: Comparison of type of soil on the settlement of soil for different opening positions

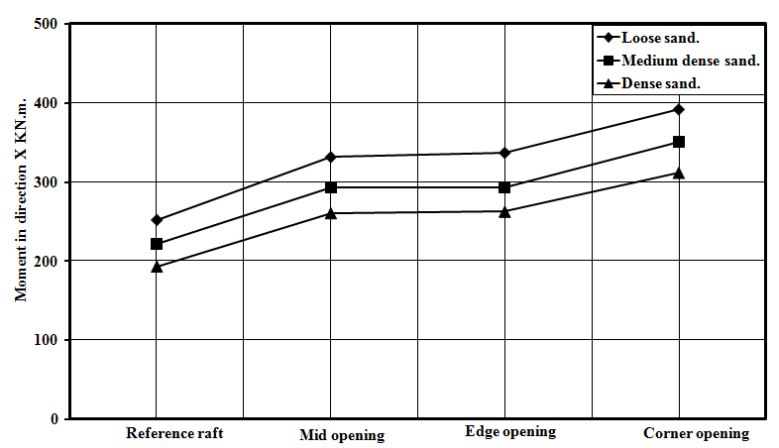

Fig 12: Effect of type of soil on the performance of the moment in direction $\mathrm{X}$ in raft foundation for different opening positions 


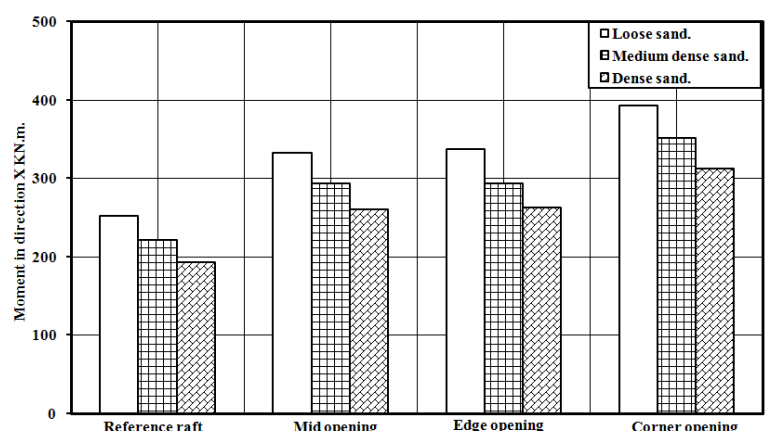

\section{Fig 13: Comparison of type of soil on the moment in direction $\mathrm{X}$ in raft foundation for different opening positions}

From the previous figures, it is noticed that:

In generally, for different types of soil, there is a increase in the settlement of soil and moment in raft for raft with mid, edge and corner openings when it is compared with the reference rafts as shown in Figs 6 to 9.

For loose sand, medium dense sand and dense sand soils, there is no much variation in the settlement of soil with mid and edge opening positions as shown in Fig. 6 and Fig. 7. The settlement of soil has the biggest values with corner opening position and it has lowest values with mid opening position.

For loose sand, medium dense sand and dense sand soils, there is no much variation in moment in raft with mid and edge opening positions as shown in Fig. 8 and Fig. 9. The moment in raft has the biggest values with corner opening position and it has lowest values with mid opening position.

For mid, edge and corner opening positions, the settlement of soil and the moment in raft have the biggest values with loose sand soil and it have the lowest values with dense sand soil as shown in Figs 10 to 13.Corner opening positions have the biggest effect on the settlement of soil and the moment in raft with loose sand and the mid opening positions have the smallest effect on the settlementof soil and the moment in raft with dense sand.

\section{CONCLUSIONS}

In this paper, the nonlinear finite elementanalysis of raft foundations resting on different types of soil has been done to study the effect ofopening position and type of soil on the behavior of raft foundations. From the results reported herein, the following conclusions are obtained:

1. Openings and type of soil have important effects on the settlementof soil and the moment in raft foundations which should be considered in design of raft foundations with opening.

2. The settlement of soil and the moment in raft increase for raft with mid, edge and corner opening positions when it is compared with the reference raft for different types of soil.

3. Mid opening positions have the smallest effect on the settlement of soil and the moment in raft while the corner opening positions have the biggest effect on the settlement of soil and the moment in raft for different types of soil.

4. Loose sand soil has the biggest effect on the settlement of soil and the moment in raft while the dense sand soil has the smallest effect on the settlement of soil and the moment in raft for different opening positions.

5. There is no much variation in the settlement of soil and moment in raft with mid and edge opening positions.

\section{REFERENCES}

[1] Andr, R.D., Ricardo, A.M., Silveira, A. and Paulo, B.2001. Numerical methods for analysis of plates on tensionless elastic foundations. International Journal of Solids and Structures 38

[2] Bhatia, K. G.2008. Foundations for industrial machines and earthquake effects. ISET Journal of Earthquake Technology, Paper No. 495, Vol. 45, No. 1-2, 13-29.

[3] Civalek, O. and Yavas, A.2006. Large deflection static analysis of rectangular plates on two parameter elastic foundations. International Journal of Science \& Technology, Vol. 1, No 1, 43-50.

[4] Civalek, O., Ozturk, B. and Yavas, A. 2007. Nonlinear transient dynamic response of clamped rectangular plates on two-parameter foundations by the algorithm of the singular convolution. International Journal of Science \& Technology, Vol. 2, No 2, 165-177.

[5] Hiroshi, M. and Takeshi, S.1987. Bending analysis of rectangular plate on non-uniform elastic foundationsStructural Eng. / Earthquake Eng, Vol.A, No.1, Japan.

[6] MandalJ, J. and Roychowdhury, S. 2008. Response of rectangular raftfoundations under transient loading. The 12th International Conference of International Association for Computer Methods and Advances in Geomechanics (IACMAG), (October 2008) India.

[7] Mehrab, J. and Mehrad, K. 2010. Comparison between numerical and analytical solution of dynamic response of circular shallow footing. EJGE, Vol. 15.

[8] PLAXIS, 3D foundation Manual Version 1, 2004.

[9] Salih, N. A.2010. Dynamics of nonlinear beam on elastic foundation. Proceedings of the World Congress on Engineering, Vol. II.

[10] Srilakshmi, G. and Rekha, B. 2011. Analysis of mat foundation using finite element method. International Journal of Earth Sciences and Engineering, Vol. 04, No. 06, pp. 113-115, October 2011. 